\title{
O profissional de apoio na rede regular de ensino: a precarização do trabalho com os alunos da Educação Especial
}

\section{The professional of support in regular education network: the precariousness of work with students in Special Education}

Silvia Maria Martins*

\begin{abstract}
* Professora do Colégio de Aplicação da Universidade Federal de Santa Catarina (UFSC) e Mestre em Educação pela mesma universidade.E-mail: s.martins@ufsc.br
\end{abstract}

\section{Resumo}

Este artigo apresenta o resultado da pesquisa de Mestrado desenvolvida durante o ano de 2010 e 2011 sobre o trabalho do profissional de apoio em turmas de Educação Infantil e Ensino Fundamental que possuem sujeitos da Educação Especial matriculados nos municípios de Florianópolis e São José. Investigou-se como a atuação destes profissionais tem sido organizada para o atendimento aos sujeitos da Educação Especial nas classes comuns. A partir desta pesquisa, foram evidenciadas as problemáticas existentes neste cargo que agregadas, constituem elementos de um processo de precarização e intensificação do trabalho docente e demonstram, de forma explícita, o modelo de inclusão escolar que está sendo difundido nas políticas nacionais para Educação Especial.

\section{Palavras-chave}

Profissional de apoio. Trabalho docente. Educação especial.

\begin{abstract}
This article presents the results of the master research developed during 2010 and 2011 about the work of the professional of support in classes of Kindergarten and Elementary School which have special students registered in Special Education in the cities of Florianópolis and São José. It was investigated how the performance of these professionals has been organized to meet to help the special students of Special Education in common classes. Considering this research, the existing problems were evidenced in this work position, if aggregated, constitute elements of a process of precariousness and intensification of teachers' work and demonstrate explicitly the model of school inclusion which is being broadcast on national policies for Special Education.
\end{abstract}

\section{Key words}

Professional of support. Teaching work. Special education. 


\section{Introdução}

O presente texto tem como propósito apresentar dados da pesquisa desenvolvida no Mestrado em Educação cujo objeto consistia no trabalho desenvolvido pelo profissional de apoio que atua com os sujeitos da Educação Especial na rede regular de ensino. A pesquisa tem como hipótese inicial que a presença do profissional de apoio tem se constituído em uma das principais estratégias desenvolvidas nas redes municipais de ensino para a realização das políticas de Educação Especial, na perspectiva inclusiva. Tal hipótese se fundamenta pela percepção da incidência do profissional de apoio nas redes mediante aproximação com o campo empírico, primeiramente nas redes municipais de ensino da Regional Grande Florianópolis em que foram coletados dados referentes às propostas políticas para a organização do cargo em suas redes.

No desenvolvimento da pesquisa procurou-se investigar a atuação do profissional de apoio em turmas de Educação Infantil e Ensino Fundamental com sujeitos da Educação Especial matriculados.

Tomou-se como campo empírico duas redes constituintes da Regional Grande Florianópolis, Florianópolis e São José, e buscou-se acessar informações com os profissionais de apoio que atuam em ambas as redes.

Pretendeu-se, portanto, investigar durante o ano de 2010, de que forma a atuação dos profissionais de apoio tem sido organizada no sentido do atendimento aos sujeitos da Educação Especial nas classes comuns, com foco nos seguintes objetivos específicos: dimensionar a incidência do profissional de apoio na classe comum na Regional Grande Florianópolis; identificar as denominações atribuídas ao profissional de apoio; analisar as atribuições previstas e realizadas para/pelo profissional de apoio; e caracterizar as condições de atuação dos profissionais de apoio em exercício. Estes objetivos contribuíram para caracterizar os profissionais de apoio na classe comum, identificando nomenclatura, formação, carga horária, atribuições, remuneração e forma de contratação. Tal aproximação possibilitou a análise da estratégia que muitas redes municipais vêm desenvolvendo para o atendimento dos sujeitos da Educação Especial na Educação Infantil e no Ensino Fundamental.

\section{Contextualização das políticas para Educação Especial no Brasil: uma análise de documentos}

A partir da década de 1990, as políticas educacionais no Brasil, e em diversos países, vêm ganhando contornos denominados como inclusivos calcados em orientações advindas de conferências internacionais, principalmente na Conferência Mundial de Educação para Todos, realizada em Jomtiem, Tailândia (UNESCO, 1990) e na Conferência Mundial sobre Necessidades Educacionais Especiais: acesso e qualidade, em 
Salamanca, Espanha (UNESCO, 1994). Porém, segundo Garcia (2004), outros documentos internacionais publicados por agências multilaterais como Banco Mundial (2000), Organização para a Cooperação e o Desenvolvimento Econômico (OCDE) (RANSON, 2001) e Organização das Nações Unidas para a Educação, a Ciência e a Cultura (UNESCO, 1990) vêm reforçar o ideário de inclusão, propondo a conquista de uma "sociedade inclusiva". O discurso que sustenta as políticas de inclusão "opera por meio de uma linguagem de mudança social, sugerindo ao leitor que estariam acontecendo modificações profundas na realidade social" (GARCIA, 2004, p. 104). No conjunto de tais proposições, a escola passa a ser concebida como um importante locus para a disseminação do ideário inclusivo.

No Brasil, em particular, esse debate ganha muita força no campo da Educação Especial com base na Declaração de Guatemala (1999) e de Nova lorque (Convenção sobre os Direitos das Pessoas com Deficiência, 2006) indicando uma mudança no sistema de ensino, visando a universalização da educação básica nos paises em desenvolvimento. A proposta de universalização contempla os sujeitos da Educação Especial como um dos grupos incorporados pela política educacional, mediante ampliação da cobertura de matrículas (MICHELS et al., 2010).

O documento das Diretrizes Nacionais para Educação Especial na Educação Básica (BRASIL, 2001), um dos primeiros a demandar aos estados e municípios a organização para o atendimento dos sujeitos da Educação Especial em suas redes de ensino, indica que uma das possibilidades para o desenvolvimento do trabalho em classe comum seja a presença de um profissional para apoiar o professor, citando este como "professor de Educação Especial”. Este deveria desempenhar seu trabalho em equipe com os professores da classe comum no atendimento aos sujeitos da Educação Especial em seu processo de ensinoaprendizagem. Já o documento da Política Nacional de Educação Especial na Perspectiva da Educação Inclusiva (BRASIL, 2008) apresenta o apoio pedagógico como "monitoria ou cuidado". Assim, ocorre uma mudança nas referências ao profissional que deveria apoiar o professor de classe no processo de ensinoaprendizagem do sujeito da Educação Especial, uma vez que este agora deve atender os alunos da Educação Especial em atividades de higiene, alimentação, locomoção e demais ações em que necessitarem de auxílio no espaço escolar. Reforçando tal proposta, no ano de 2010, a SEESP divulgou uma nota técnica destinada aos profissionais de apoio para alunos com deficiência e transtornos globais do desenvolvimento matriculados nas escolas comuns da rede pública de ensino em que demanda uma ação de cuidado e de monitoria a atendimento as questões "no âmbito da acessibilidade às comunicações e de atenção aos cuidados pessoais de alimentação, higiene e locomoção" (BRASIL, 2010, p. 
01). Diante das novas orientações para a função de profissional de apoio, podese considerar que de apoio ao professor na classe comum para a organização do trabalho pedagógico a ser realizado neste espaço, o profissional de apoio passou a monitoria e cuidado do sujeito da Educação Especial matriculado nas classes regulares de ensino.

As normativas mais recentes ${ }^{1}$ voltadas à Educação Especial demandam uma forte imposição de que o AEE nas redes de ensino aconteça nas salas de recursos multifuncionais (BRASIL, 2008, 2009). Tal ênfase enfraquece o trabalho da Educação Especial na classe regular, o qual perdeu a possibilidade de apoio pedagógico especializado e passou a assumir o formato de monitoria e cuidado. A Secretaria Municipal de Educação de Florianópolis possui uma forte organização em termos de sala de recursos, que conforme se pode perceber a partir dos dados da pesquisa, é o local privilegiado para o desenvolvimento do atendimento educacional especializado, haja vista a forte caracterização em termos de monitoria e cuidado evidenciado nos relatos dos profissionais de apoio contratados para atuarem nas classes regulares junto aos sujeitos da Educação Especial entrevistados nessa rede. O município de São José possui o NEESPI com profissionais

\footnotetext{
${ }^{1}$ Esta pesquisa não incorporou o último decreto 7.611/2011, porém este documento também não enfatiza o trabalho na classe comum, apenas reafirma que o $A E E$ aconteça nas salas de recursos multifuncionais.
}

especializados que segundo o "Caderno pedagógico: Educação Inclusiva" atende os alunos sujeitos da Educação Especial com oferecimento do AEE e orientações às escolas da rede municipal de ensino "no que se refere à educação inclusiva, através de assessorias sistemáticas [...]" (SÃO JOSÉ, 2009, p. 19). Embora o município de São José apresente questões pedagógicas no desenvolvimento do trabalho dos profissionais de apoio nas classes regulares, ao menos prescrito, não foi o que se constatou a partir das falas dos profissionais de apoio entrevistados na rede. A denúncia de abandono por parte do NEESPI às questões que se apresentavam nas escolas referentes aos sujeitos da Educação Especial foram fortemente destacadas. Portanto, o modelo atual para o atendimento educacional especializado encontrado em ambas as redes que serviram de lócus para a pesquisa se destaca por um trabalho realizado de forma independente daquele realizado na classe regular.

\section{Caracterização dos profissionais de apoio da amostra da pesquisa em Florianópolis e São José}

No município de Florianópolis foram entrevistados 22 auxiliares de ensino de Educação Especial, abarcando uma amostra de $26,5 \%$ do total da rede municipal de educação que contabiliza 83 profissionais. Dos 22 auxiliares entrevistados apenas dois são do sexo masculino o que demonstra uma forte presença feminina nesta função. Na 
rede municipal de educação de São José foram entrevistados 19 auxiliares de ensino para educandos com deficiência, todas do sexo feminino, abarcando uma amostra de $22 \%$ do total dos profissio- nais de apoio em foco atuantes na rede, os quais somam 86 .

Na tabela 1 apresenta-se o número total de auxiliares distribuídos nas duas redes de ensino pesquisadas.

Tabela 1 - Número de profissionais de apoio atuantes nas redes municipais de educação de Florianópolis e São José por categoria e etapa educacional

\begin{tabular}{c|l|c|c|c|c}
\hline Município & \multicolumn{1}{|c|}{$\begin{array}{c}\text { Profissional de } \\
\text { apoio }\end{array}$} & $\begin{array}{c}\text { Educação } \\
\text { Infantil }\end{array}$ & $\begin{array}{c}\text { Ensino } \\
\text { Fundamental }\end{array}$ & $\begin{array}{c}\text { Sub- } \\
\text { total }\end{array}$ & Total \\
\hline \multirow{2}{*}{ Florianópolis } & $\begin{array}{l}\text { Auxiliar de ensino } \\
\text { de Ed. Especial Fixo }\end{array}$ & 23 & 38 & 61 \\
\cline { 2 - 6 } & $\begin{array}{l}\text { Auxiliar de ensino } \\
\text { de Ed. Especial } \\
\text { Volante }\end{array}$ & 04 & 18 & 22 \\
\cline { 2 - 6 } & Sub-total & 27 & 56 & \\
\hline \multirow{2}{*}{ São José } & $\begin{array}{l}\text { Auxiliar de ensino } \\
\text { para educandos } \\
\text { com deficiência }\end{array}$ & 17 & 69 & 86 \\
\hline
\end{tabular}

Fonte: Dados fornecidos pela Gerência de Educação Inclusiva do município de Florianópolis e Secretaria Municipal de Educação de São José.

O município de Florianópolis possui duas categorias de auxiliar de ensino de Educação Especial: "volantes" e "fixos". Os auxiliares volantes podem atender até três crianças, em turmas diferentes no mesmo período e na mesma instituição. Os auxiliares fixos desempenham seu papel especificamente em uma turma, podendo nesta sala frequentar um ou mais sujeitos da Educação Especial. Não há uma pré-seleção para a função de auxiliar fixo ou volante, dependendo exclusivamente da demanda de alunos da unidade educacional. Conforme informação recebida pela Gerência de Educação Inclusiva do município de Florianópolis, todos os auxiliares são contratados como volantes, porém o que define se acompanhará uma ou mais turmas é a demanda de cada unidade e as especificidades dos alunos.

A Tabela 1 evidencia que o auxiliar volante é uma alternativa bastante utilizada na rede municipal de Florianópolis, principalmente no Ensino Fundamental que conta com 18 profissionais de apoio, totalizando $21 \%$ do total de 83 auxiliares de ensino de Educação Especial naquele município, embora predominem os auxiliares fixos.

Os auxiliares de ensino de Educação Especial podem atuar em mais de uma etapa educacional, mas os dados gerais da rede municipal de 
Florianópolis indicam um predomínio de atuação no Ensino Fundamental, o que é esperado ao considerar que é no Ensino Fundamental que o número de alunos é maior, assim como o número de alunos que demandam o trabalho do profissional de apoio. Uma hipótese para a variação no número de profissionais de apoio para Educação Infantil com relação ao Ensino Fundamental refere-se à presença de um auxiliar de sala para as classes de Educação Infantil. Sendo assim, já há a presença de um profissional a mais nestas classes, além do professor.

O Quadro 1 apresenta o número de profissionais de apoio presentes nas redes de ensino pesquisadas, além das matrículas de alunos das redes municipais e o número de crianças da Educação Especial matriculadas nas escolas regulares em cada município.

\begin{tabular}{|c|c|c|c|c|c|c|c|c|c|c|c|c|}
\hline \multirow[b]{3}{*}{ Município } & \multicolumn{4}{|c|}{ Ed. Infantil } & \multicolumn{4}{|c|}{ Ens. Fundamental } & \multirow{2}{*}{\multicolumn{4}{|c|}{$\begin{array}{l}\text { Educação Especial } \\
\text { (alunos de escolas especiais, } \\
\text { classes especiais e incluídos) }\end{array}$}} \\
\hline & \multicolumn{2}{|c|}{$\begin{array}{l}\text { Matrícula } \\
\text { inicial de } \\
\text { alunos }\end{array}$} & \multirow[b]{2}{*}{ Docentes } & \multirow[b]{2}{*}{ P.A } & \multicolumn{2}{|c|}{$\begin{array}{l}\text { Matrícula } \\
\text { inicial de } \\
\text { alunos }\end{array}$} & \multirow[b]{2}{*}{ Docentes } & \multirow[b]{2}{*}{ P.A } & & & & \\
\hline & Creche & $\begin{array}{c}\text { Pré- } \\
\text { escola }\end{array}$ & & & $\begin{array}{c}\text { Anos } \\
\text { Iniciais }\end{array}$ & \begin{tabular}{|l|} 
Anos \\
Finais
\end{tabular} & & & Creche & \begin{tabular}{|c|} 
Pré- \\
escola
\end{tabular} & \begin{tabular}{|c|} 
Anos \\
Iniciais
\end{tabular} & $\begin{array}{l}\text { Anos } \\
\text { Finais } \\
\end{array}$ \\
\hline Florianópolis & 4.630 & 5.253 & 394 & 27 & 7.516 & 7.704 & 660 & 56 & 43 & 55 & 113 & 100 \\
\hline São José & 1.669 & 2.879 & 304 & 17 & 6.725 & 6.499 & 629 & 69 & 14 & 26 & 101 & 48 \\
\hline
\end{tabular}

Quadro1 - Matrícula inicial de alunos das redes municipais de ensino e número de docentes e profissionais de apoio nos níveis/etapas de Educação Infantil e Ensino Fundamental nos municípios pesquisados/2010.

Fonte: INEP/ Censo Escolar/ 2009 e IBGE cidades. Docentes/2009.

Os dados apontam que São José é o município que possui o maior número de profissionais de apoio atuando no Ensino Fundamental, já o município de Florianópolis, possui o maior número destes profissionais na Educação Infantil. Verifica-se por estes dados que a rede de São José se utiliza mais do trabalho do profissional de apoio que a rede de Florianópolis, tendo em vista o número de alunos sujeitos da Educação Especial atendidas pelos referidos municípios. O Município de Florianópolis possui 27 profissionais de apoio para atender 98 sujeitos da Educação Especial matriculados na Educação Infantil, sendo que São José possui 17 profissionais de apoio para atender 40 sujeitos da Educação Especial, matriculados na mesma etapa/nível educacional. No Ensino Fundamental, a rede municipal de Florianópolis possui 56 profissionais de apoio para atender 213 sujeitos da Educação Especial matriculados, já São José possui 69 profissionais de apoio contratados para atender 149 sujeitos da Educação Especial. 
Uma possível explicação para tal fato é que a contratação deste profissional no município de São José acontece tendo por prioridade os casos diagnosticados com deficiência mental e/ou deficiência múltipla, o que amplia as possibilidades de "enquadramento" das características dos sujeitos. Já no município de Florianópolis, para que uma classe receba um auxiliar de ensino de Educação Especial, é necessário que esteja matriculado um sujeito da Educação Especial que apresente dependência na locomoção e/ou na higiene e/ou na alimentação e/ou ter risco de morte, o que acaba por delimitar em grande medida os casos a serem atendidos no município.

Retomando os dados apresentados no Quadro 1 foram contabilizados na rede municipal de Florianópolis, no ano de 2010, 311 crianças da Educação Especial matriculadas nas diferentes etapas de ensino, Educação Infantil e Ensino Fundamental, e 83 profissionais de apoio na rede. Já na rede municipal de São José, conforme os dados coletados, são 189 crianças matriculadas nas diferentes etapas de ensino que contam com o trabalho de 86 profissionais de apoio. É possível afirmar, ainda, a partir de tais dados, que o trabalho do profissional de apoio fica restrito à monitoria e ao cuidado, há, também, insuficiência de profissionais para o atendimento aos sujeitos da Educação Especial, indicando uma grande disparidade principalmente em relação aos dados de Florianópolis que apresentam 83 auxiliares para 311 crianças.

O número de profissionais de apoio volantes em relação aos fixos representa $1 / 3$. Porém, ao analisar a quantidade de crianças atendidas por esses profissionais de apoio contratados como volantes, percebe-se que para exercer a função que cinco volantes entrevistados realizam seriam necessários ao menos mais 16 auxiliares fixos. Tal número tomaria proporções muito maiores, caso fossem analisados dados referentes à quantidade de crianças atendidas por todos os 22 volantes na rede de Florianópolis.

Serão apresentadas, no Quadro 2, a nomenclatura e as atribuições do profissional que presta apoio ao professor regente em classe com sujeitos da Educação Especial em cada município. 


\begin{tabular}{|c|c|c|c|}
\hline & Municípios & Nomenclatura & Atribuições \\
\hline 01 & Florianópolis & $\begin{array}{l}\text { Auxiliar de ensino } \\
\text { de Educação } \\
\text { Especial }\end{array}$ & $\begin{array}{l}\text { "I-Participar de reuniões pedagógicas, conselhos de } \\
\text { classe, planejamentos e de grupos de estudos na } \\
\text { unidade educativa; [...] III -Aplicar e utilizar os materiais } \\
\text { e recursos de Comunicação Aumentativa Alternativa e } \\
\text { Tecnologia Assistiva fornecidos pelos professores das Salas } \\
\text { Multimeios; [...] V - Auxiliar o(s) aluno(s) com deficiência } \\
\text { em sua alimentação, de acordo com as orientações } \\
\text { do profissional especializado que o (s) acompanha } \\
\text { (m);VI - Auxiliar o(s) aluno(s) em sua higiene conforme } \\
\text { orientações do profissional especializado que acompanha } \\
\text { o(s) mesmo(s), de acordo com as particularidades de } \\
\text { cada aluno; VII - Auxiliar o(s) aluno(s) em sua locomoção: } \\
\text { conduzir a cadeira de rodas, apoiá-lo quando caminhar, } \\
\text { ainda que tenha dificuldade e/ou colocá-lo e acompanhá- } \\
\text { lo no andador, de acordo com as orientações do } \\
\text { profissional especializado que acompanha o(s) aluno(s) } \\
\text { [...]" (FLORIANÓPOLIS, 2007, p. 4). }\end{array}$ \\
\hline 02 & São José & $\begin{array}{l}\text { Auxiliar de ensino } \\
\text { para educandos } \\
\text { com deficiência }{ }^{2}\end{array}$ & $\begin{array}{l}\text { "Auxiliar o 10 professor no processo de ensino- } \\
\text { aprendizagem de todos os alunos, especificamente aos } \\
\text { alunos com diagnóstico de deficiência: Ser mediador do } \\
\text { conhecimento, auxiliando e orientando os alunos da turma } \\
\text { em conjunto com o 10 professor; Participar da discussão } \\
\text { do planejamento junto com o 10 professor e o supervisor } \\
\text { escolar; O planejamento não deve ser diferenciado para } \\
\text { nenhum aluno. O planejamento e as adaptações das } \\
\text { estratégias devem ser discutidos por ambos, } 10 \text { professor } \\
\text { e 20 professor; Devem ser possibilitadas trocas constantes } \\
\text { entre o } 10 \text { professor e o } 20 \text { professor no trabalho com } \\
\text { os alunos com deficiência; Não é recomendado trabalho } \\
\text { diferenciado e individualizado com o aluno com deficiência } \\
\text { em sala de aula ou em qualquer outro momento; Cabe ao } \\
10 \text { professor e } 20 \text { professor a responsabilidade de avaliar } \\
\text { o aluno com diagnóstico de deficiência; O } 20 \text { professor irá } \\
\text { acompanhar os alunos (turma) em todas as aulas, ou seja, } \\
\text { educação física, educação artística, língua estrangeira, etc" } \\
\text { (SÃO JOSÉ, 2009, p. 1). }\end{array}$ \\
\hline
\end{tabular}

Quadro 2 - Nomenclatura e atribuições do profissional de apoio nos municípios investigados.

${ }^{2}$ A Secretaria de Educação utilizava a nomenclatura segundo professor para designar o profissional de apoio que em 2010 passou a ser denominado Auxiliar de ensino para educandos com deficiência.
Conforme evidenciado, existem variadas atribuições, bem como nomenclaturas para designar o profissional que presta apoio ao trabalho dos professores regentes nas turmas de Ensino Fundamental e Educação Infantil. Também nos 
documentos representativos da Política Nacional de Educação Especial, na perspectiva da Educação Inclusiva (BRASIL, 2008, 2009), são encontradas diferentes denominações para este sujeito como: profissionais da educação para a inclusão, cuidador, monitor, profissionais da educação que atuem no apoio e profissional de apoio (BRASIL, 2010).

No que se refere às atribuições previstas para o cargo dos profissionais de apoio podemos destacar que em Florianópolis predomina a característica de cuidado já em São José são mais fortemente destacada características pedagógicas. Embora nas entrevistas realizadas com as profissionais Auxiliar de ensino para educandos com deficiência não tenha sido percebida diferenciação em suas atribuições.

A formação exigida para o exercício destes profissionais também foi foco de análise. Florianópolis e São José admitem, para a função, profissionais com formação em ensino médio (Magistério). Em São José (2009), o edital no 008/2009, de processo seletivo para substitutos da rede, evidencia a ampla diversificação da formação exigida ao candidato à vaga de auxiliar de ensino para educandos com deficiência, o qual pode ter graduação em Pedagogia com habilitação em Educação Especial ou simplesmente formação em nível médio/magistério.

\begin{tabular}{|c|c|l|}
\hline & Municípios & \multicolumn{1}{c|}{ Formação Inicial exigida para contratação } \\
\hline 01 & Florianópolis & $\begin{array}{l}\text { Formação no ensino médio em Magistério, ou graduado ou estudante da } \\
\text { 5a fase em diante dos cursos de graduação em licenciaturas na área da } \\
\text { Educação. (FLORIANÓPOLIS. Edital no 003/2009 - Processo seletivo de } \\
\text { substitutos) } \\
\text { Diploma ou certificado de conclusão do curso de licenciatura Plena na área } \\
\text { de Educação (FLORIANÓPOLIS. Edital no 001/2009 - Concurso público). }\end{array}$ \\
\hline 02 & São José & $\begin{array}{l}\text { Licenciatura em Pedagogia ou Normal Superior, com habilitação em } \\
\text { Educação Especial; ou Formação no Ensino Médio, com habilitação } \\
\text { em Magistério (SÃO JOSÉ. Edital no 008/2009 - Processo seletivo de } \\
\text { substitutos). }\end{array}$ \\
\hline
\end{tabular}

Quadro 3 - Formação inicial dos profissionais de apoio nos municípios pesquisados.

As redes de Florianópolis e São José aceitam a formação em nível médio, porém não são homogêneas entre si quanto às atribuições dos profissionais, já que variam desde auxiliar os alunos nas questões relacionadas à higiene e cuidado até o trabalho pedagógico junto ao professor de classe comum.

Outro ponto que merece destaque refere-se à forma de contratação destes profissionais, cujos dados serão apresentados no Quadro 4. 


\begin{tabular}{|c|c|l|}
\hline & Municípios & \multicolumn{1}{c|}{ Forma de Contratação } \\
\hline 01 & Florianópolis & $\begin{array}{l}\text { Concurso público e processo seletivo simplificado específico para a } \\
\text { função. (Depoimento Gerente de Educação Inclusiva em 10/03 /2010). }\end{array}$ \\
\hline 02 & São José & $\begin{array}{l}\text { Processo seletivo simplificado específico para esta função. (Depoimento } \\
\text { Coordenadora do Núcleo de Educação Especial e Inclusiva em } \\
29 / 03 / 2010) .\end{array}$ \\
\hline
\end{tabular}

Quadro 4 - Forma de contratação dos profissionais de apoio nos municípios pesquisados.

Quanto à forma de contratação ambos municípios realizam processo seletivo e concurso público específicos para o desempenho da função. Porém cabe destacar que no inicio desta pesquisa o município de São José selecionava da listagem dos candidatos de processo seletivo para contrato temporário no cargo de professor regente, neste momento a entrevistada, responsável pela "educação inclusiva" do município expôs a angústia de alguns candidatos ao saberem que não desempenhariam o papel de professor de classe, mas de profissional de apoio, já que este último não recebe gratificação de incentivo a regência de classe $^{3}$. Atualmente, este município desenvolve processo seletivo simplificado

\footnotetext{
${ }^{3} \mathrm{~A}$ gratificação de incentivo à regência de classe é uma vantagem de ordem pecuniária concedida ao professor em efetivo exercício em sala de aula, que atue na educação infantil, ensino fundamental (1a a 4a á série), educação especial, educação física e educação de jovens e adultos (nivelamento/alfabetização), em razão do trabalho realizado, equivalente a $40 \%$ (quarenta por cento) do vencimento do cargo efetivo, correspondente à carga horária de efetivo exercício em regência de classe, podendo variar nas redes municipais de ensino. Disponível em: <http://www.sea.sc.gov. br> Acesso em: 20 mar. 2010.
}

para provimento de vagas ao cargo de profissional de apoio na rede.

Também se buscou conhecer a remuneração desses profissionais. Embora dos 22 entrevistados no município de Florianópolis apenas três trabalhem 20 horas, neste quadro, foram contabilizados também como 20 horas aqueles que trabalham em outras redes de ensino, ou em outras funções nas 20 horas restantes de sua carga horária, já que o interesse é analisar a remuneração dos auxiliares neste cargo.

A remuneração dos profissionais de apoio foi considerada pelos entrevistados, em ambos os municípios, como mais uma das formas de desvalorização profissional. Os próprios profissionais consideram a remuneração recebida como extremamente baixa, o não recebimento dos $40 \%$ de regência de classe é considerado injusto por parte dos auxiliares de ensino de Educação Especial no município de Florianópolis, já que trabalham com a mesma carga horária do professor regente de classe, sendo que em alguns casos precisam acompanhar a criança nos momentos do recreio para auxílio à locomoção, alimentação e higiene. 


\begin{tabular}{|c|c|c|c|}
\hline $\begin{array}{c}\text { Remuneração dos auxiliares de } \\
\text { ensino de Educação Especial }\end{array}$ & $\mathbf{2 0}$ horas & $\mathbf{4 0}$ horas & Situação funcional \\
\hline De $R \$ 500,00$ a $R \$ 700,00$ & 05 & - & Substitutos \\
\hline De $R \$ 1.000,00$ a $R \$ 1.500,00$ & - & 13 & Substitutos \\
\hline Acima de $R \$ 2.000,00$ & - & 01 & Efetivo \\
\hline
\end{tabular}

Quadro 5 - Remuneração dos auxiliares de ensino de Educação Especial da rede municipal de Florianópolis.

No município de São José, não há o cargo de auxiliar de ensino de educandos com deficiência com a situação funcional efetivo, apenas por contrato temporário, diferentemente de Florianópolis que realiza concurso público para desempenho deste cargo.

\begin{tabular}{|c|c|c|c|}
\hline $\begin{array}{c}\text { Remuneração dos auxiliares de ensino } \\
\text { para educandos com deficiência }\end{array}$ & $\mathbf{2 0}$ horas & $\mathbf{4 0}$ horas & Situação funcional \\
\hline De $\mathrm{R} \$ 700,00$ a $\mathrm{R} \$ 850,00$ & 13 & - & Substitutos \\
\hline De $\mathrm{R} \$ 1.000,00$ a $\mathrm{R} \$ 1.800,00$ & - & 06 & Substitutos \\
\hline
\end{tabular}

Quadro 6 - Remuneração dos auxiliares de ensino para educandos com deficiência da rede municipal de São José.

Ao analisar os dois quadros, podese perceber que não há grande variação nos salários recebidos pelos profissionais de apoio atuantes nas duas redes de ensino pesquisadas, considerando que a informação foi obtida mediante declaração dos entrevistados e não houve acesso aos comprovantes de rendimento profissional dos mesmos. A diferença de valores encontrada refere-se à situação funcional dos profissionais de apoio apenas nas formas de contratação (de substituto para efetivo).

Outro tópico a ser analisado refere-se à carga horária de trabalho semanal dos profissionais de apoio que atuam nas duas redes. A maioria dos auxiliares entrevistados em Florianópolis atua 40 horas semanais, uma vez que apenas 13,64\% (três) dos 22 entrevistados atuam 20 horas. Contudo, entre os entrevistados que atuam 40 horas semanais, cinco trabalham em outros cargos além do de auxiliar de ensino de Educação Especial, tais como professor de classe regular de redes públicas, assistente técnico pedagógico e professores de escolas privadas. Foram contabilizados 14 auxiliares com 40 horas semanais na função de profissional de apoio, dentre estes, um atua como profissional de apoio na rede pública estadual.

Em São José, há grande incidência de profissionais da Educação Infantil 
atuando 50 horas semanais, acumulando os cargos de professor ou auxiliar de sala na Educação Infantil em um período e de auxiliar de ensino para educandos com deficiência em outro.

\begin{tabular}{|l|c|c|}
\hline \multicolumn{1}{|c|}{ Carga horária semanal } & $\begin{array}{c}\text { Número de Auxiliares } \\
\text { de ensino de educação } \\
\text { Especial (Florianópolis) }\end{array}$ & $\begin{array}{c}\text { Número de Auxiliar de } \\
\text { ensino para educandos } \\
\text { com deficiência (São José) }\end{array}$ \\
\hline 20 horas & 03 & 01 \\
\hline 40 horas com cargos diferentes & 05 & 02 \\
\hline 40 horas como auxiliar & 14 & 07 \\
\hline $\begin{array}{l}50 \text { horas (20h auxiliar e 30h como } \\
\text { professora ou auxiliar de ensino } \\
\text { na Ed. Infantil). }\end{array}$ & - & 09 \\
\hline
\end{tabular}

Quadro 7 - Carga horária semanal dos auxiliares de ensino de Educação Especial de Florianópolis e auxiliares de ensino para educandos com deficiência de São José.

Das 19 entrevistadas na rede municipal de São José, sete atuam 40 horas na função de auxiliar de ensino para educandos com deficiência, sendo que uma destas atua como profissional de apoio na rede estadual. Duas atuam 20 horas na função de profissional de apoio e demais 20 horas em outras funções.

Quanto à formação dos profissionais de apoio os dados demonstram que, principalmente na rede municipal de Florianópolis, poucos não possuem cursos de pós-graduação lato sensu, e destes alguns já estão cursando. Já no município de São José o maior número de profissionais entrevistados possui graduação incompleta. Estes dados poderão ser melhor analisados com base nos dados do Quadro 8.

\begin{tabular}{|l|c|c|}
\hline \multicolumn{1}{|c|}{ Formação } & $\begin{array}{c}\text { Quantidade de auxiliares } \\
\text { de ensino de Educação } \\
\text { Especial } \\
\text { (Florianópolis) }\end{array}$ & $\begin{array}{c}\text { Quantidade de auxiliares de } \\
\text { ensino para educandos com } \\
\text { deficiência } \\
\text { (São José) }\end{array}$ \\
\hline Ensino Médio & - & 02 \\
\hline $\begin{array}{l}\text { Graduação incompleta } \\
\text { (cursando) }\end{array}$ & 02 & 07 \\
\hline Graduação & 04 & 02 \\
\hline $\begin{array}{l}\text { Pós-graduação incompleta } \\
\text { (cursando) (lato sensu) }\end{array}$ & 05 & 03 \\
\hline Pós-graduação (lato sensu) & 12 & 05 \\
\hline
\end{tabular}

Quadro 8 - Formação dos Auxiliares de Ensino de Educação Especial e auxiliares de ensino para educandos com deficiência. 
Neste tópico, o entrevistado respondia acerca de seu maior nível de escolaridade. Nenhum dos entrevistados possuía formação inferior à graduação no município de Florianópolis, já em São José foram encontradas duas profissionais cujo maior nível de formação era o Ensino Médio. Em Florianópolis, um dos entrevistados que é indicado no quadro como "graduação incompleta" está cursando concomitante à pós-graduação (este foi contabilizado nas duas categorias). Dos quatro respondentes contabilizados em "graduação completa", um está, no momento, cursando sua segunda graduação, agora em Pedagogia, já que possui graduação em Letras. Este entrevistado foi contabilizado uma vez por referir-se ao mesmo nível de escolaridade. Ainda neste mesmo município, cinco entrevistados cursam pós-graduação em nível de especialização lato sensu, cujas temáticas estão relacionadas à Educação Especial. Dentre os 12 que já possuem pós-graduação, também lato sensu, há grande variedade de temáticas dos cursos tais como Educação Infantil e Séries Iniciais, Educação Infantil e Séries Inicias com ênfase em Educação Especial, Gestão Escolar, Educação de Jovens e Adultos, Psicopedagogia, Interdisciplinaridade na Educação Infantil e Séries Iniciais, Psicomotricidade, Educação Especial e Gestão e Interdisciplinaridade.
Das sete que estão cursando graduação no município de São José, cinco cursam Pedagogia, uma profissional de apoio está cursando História e uma está cursando Letras. Dentre aquelas que já concluíram a graduação, oito possuem formação em Pedagogia e duas em Biblioteconomia. As pós-graduações que estão em curso são em nível de especialização lato sensu, destas, duas cursam Educação Infantil e Séries iniciais com ênfase em Educação Especial, e outra Educação Infantil e Séries Iniciais: Gestão e Ensino Médio. Uma das entrevistadas que já possui pós-graduação em Estrutura e Funcionamento dos Estudos de 1ㅇ, 2ㅇ e 3으 grau está cursando sua segunda especialização em Educação Infantil. Esta entrevistada foi contabilizada uma vez por referir-se ao mesmo nível de escolaridade. Das cinco que já possuem pós-graduação, uma é formada em Psicopedagogia, uma em Práticas de Ensino e outra em Educação Infantil e Séries Iniciais.

Quanto à graduação dos auxiliares no município de Florianópolis, a predominância é o curso de Pedagogia, com uma significativa margem de diferença dos demais cursos. Dos entrevistados, quatro são graduados em Educação Física, dois em Letras e um em Geografia. Vale ressaltar que um dos graduados que na tabela é indicado com graduação em Letras também está cursando Pedagogia. 


\begin{tabular}{|l|c|c|}
\hline \multicolumn{1}{|c|}{ Graduação em: } & $\begin{array}{c}\text { Quantidade de auxiliares de } \\
\text { ensino de Educação Especial } \\
\text { (Florianópolis) }\end{array}$ & $\begin{array}{c}\text { Quantidade de auxiliares de } \\
\text { ensino para educandos com } \\
\text { deficiência } \\
\text { (São José) }\end{array}$ \\
\hline Pedagogia & 15 & 08 \\
\hline Educação Física & 04 & - \\
\hline Letras & 02 & - \\
\hline Biblioteconomia & - & 02 \\
\hline Geografia & 01 & - \\
\hline
\end{tabular}

Quadro 9 - Cursos de graduação dos auxiliares de ensino de Educação Especial da rede de Florianópolis e auxiliar de ensino para educandos com deficiência do município de São José.

Os dados apontam que, em ambas as redes investigadas, a formação dos profissionais de apoio no desenvolvimento do trabalho com os sujeitos de Educação Especial em classe pode variar em diferentes áreas, o que pode representar uma indefinição do perfil profissional. Por outro lado, tal aspecto pode ser significado como uma ausência dos aspectos pedagógicos presentes nas propostas que proclamam a Educação Especial na perspectiva inclusiva. Michels et al. (2010) discutem a restrição dos processos de aprendizagem como consequência de um empobrecimento dos conteúdos trabalhados na educação básica e da falta dos aspectos pedagógicos que vem diluindo-se nos discursos presentes nas propostas da SEESP para a educação escolar de alunos da Educação Especial.

Deste modo, ao se considerar o empobrecimento nas questões pedagógicas divulgadas pelos documentos orientadores e normativos das políticas nacionais voltados para a Educação Especial na perspectiva inclusiva, não há realmente nenhum impedimento para o profissional de apoio ser formado em Educação Física, Letras, Geografia ou Biblioteconomia, já que o desenvolvimento do trabalho com os sujeitos da Educação Especial se resume à monitoria, não sendo necessária, deste modo, uma formação específica.

Entretanto, se entendemos que a escola é o espaço privilegiado para a aquisição de conhecimentos historicamente acumulados e sistematizados, como não pensar no aspecto pedagógico na educação destas e demais crianças presentes nesse espaço educacional? As políticas para a Educação Especial numa perspectiva inclusiva enfatizam, conforme seus documentos representativos, a importância da socialização da criança nas classes comuns e deposita no atendimento educacional especializado, fora da classe regular, a grande contribuição para que a criança esteja "incluída" na 
escola. A força dessa política consiste na criação de serviços públicos para o atendimento desses sujeitos, o que acaba não rompendo com o antigo modelo de atendimento na Educação Especial marcado pela segregação.

Pode-se relacionar os elementos aqui apresentados como empobrecimento nas questões pedagógicas, ausência de formação específica para atuar no cargo atrelado a uma indefinição do perfil profissional à categoria de desintelectualização do professor, tal como discutida por Shiroma (2003), como processo gradativo que vem se instalando no sistema educacional brasileiro por meio de redução de exigências de qualificação ou formação aligeirada que contribui para uma proposta de educação pouco alicerçada nos aspectos pedagógicos. A autora discute a função político-ideológica do conceito de profissionalização cunhado na política de formação dos professores para a educação básica no Brasil elaborada a partir do Governo de Fernando Henrique Cardoso (1995-2002) e que se materializou nas orientações advindas do documento "Propostas de diretrizes para a formação inicial da educação básica, em cursos de nível superior" lançado em 2001 pelo Conselho Nacional de Educação. O referido documento constitui-se de mais uma das iniciativas oficiais na implantação de um projeto político educacional para a formação docente cujo desenvolvimento deva se dar sob a forma de "[...] conhecimento experiencial designado como conhecimento construído 'na' e 'pela' experiência" (SHIROMA, 2003, p. 03). Assim, como exposto pela autora, temse observado que tais ideias mantêm-se presentes para com os profissionais de apoio que vêm atuando nas escolas, sua formação deve se dar através da experiência desprovida da teoria no manejo com os sujeitos da Educação Especial.

\section{Considerações finais}

A partir da verticalização deste estudo, foi possível aprofundar as questões relativas à caracterização dos profissionais de apoio que atuam com os sujeitos da Educação Especial matriculados nas classes regulares de ensino. Tal aprofundamento possibilitou visualizar a desvalorização destes profissionais de forma mais ampliada e sistematizada. No tópico referente à forma de contratação, observou-se que na rede de Florianópolis o profissional de apoio pode exercer seu cargo em mais de uma turma no atendimento as crianças com as mais diferentes necessidades, o que caracteriza a complexidade da função. Já em São José, no que se refere à forma de contratação, o que chama a atenção é a não contratação por concurso público, isto é, o profissional de apoio, a cada ano, precisa passar por processo seletivo para permanecer no cargo, o que evidencia a rotatividade, consequência da não adaptação e/ou ausência de estratégias para sustentar estes profissionais no exercício da função.

A rede de Florianópolis ainda possui em seu quadro funcional uma 
forma de organização do modo de função denominado "volante" que retira do profissional de apoio qualquer possibilidade de que este possa desenvolver seu trabalho voltado aos aspectos pedagógicos com os sujeitos da Educação Especial. Tal debate trouxe à tona a problemática da intensificação do trabalho docente que se refere à sobrecarga de trabalho que nas últimas décadas passaram a fazer parte das jornadas de trabalho dos professores. Oliveira et al. (s/d, p. 7) discutem o tema e acrescentam que:

Tudo isso vem somar a condições extremamente extenuantes de trabalho em que o professor já era submetido, extrapolando muitas vezes ao que é prescrito como sua atividade. Isto ocorre porque a escola pública no Brasil constitui-se em uma política pública "eficiente", no sentido da sua extensão, ou seja, ela chega até os pobres e, por isso mesmo, traz para os professores outras tarefas que vão além do que determina sua função: cuidar da higiene, da nutrição, da saúde, entre outras necessidades dos seus alunos.

O conceito de intensificação, segundo Marin (2010), encontra-se nas caracterizações da precarização do trabalho docente, juntamente com tantas outras que tem constituído a atuação docente nas escolas e que foram identificadas a partir dos relatos dos profissionais de apoio entrevistados nas redes de ensino público municipal de Florianópo- lis e São José. Variadas foram as formas que constituíam a precária condição de trabalho dos profissionais de apoio que são contratados para atuarem junto aos sujeitos da Educação Especial. Algumas questões foram identificadas nos municípios investigados e evidenciam a precarização do trabalho no espaço escolar como: ausência de propostas governamentais que regularizem o cargo em alguns municípios, sobrecarga de trabalho ocasionado pelo número insuficiente de profissionais contratados para atuarem nas escolas, ausência de formação específica para atuar no cargo, baixa remuneração, ausência de espaços adaptados ao atendimento dos sujeitos da Educação Especial matriculados nas classes regulares.

A desintelectualização indicada por Shiroma (2003) pode referir-se à ausência de apoio à qualificação, e ainda à valorização do treinamento, da prática em detrimento do conhecimento teórico, elementos também evidenciados nos relatos dos profissionais de apoio.

Das caracterizações indicadas por Marin (2010) para identificar a precarização do trabalho docente a que mais fortemente foi identificada nos relatos dos entrevistados foi a categoria "desvalorização". Esta categoria é apresentada sob diferentes formas, desde baixa remuneração até a forma de contratação destes profissionais, já que não é exigida formação especializada para atuar no cargo de profissional de apoio. O Outro destaque refere-se a não valorização do trabalho do profissional de apoio pelos 
demais funcionários da instituição que os tratam como se fossem os únicos responsáveis pelo sujeito da Educação Especial matriculado na instituição. A responsabilização abrange desde questões relacionadas à aprendizagem dessas crianças, mas principalmente aos aspectos relacionados ao atendimento às necessidades básicas destes alunos, como ir ao banheiro, alimentação, higiene e locomoção.

No que se refere à formação continuada, os profissionais de apoio destacaram sobre o direcionamento conferido aos cursos que tratam de forma bastante enfática dos aspectos diagnósticos. Ou seja, os cursos oferecidos aos profissionais de apoio, em ambas as redes, foram considerados, pelos profissionais de apoio entrevistados, como de pouca ou nenhuma ajuda ao trabalho desenvolvido nas classes, já que não há presença de aspectos pedagógicos nestes cursos, o que acaba por seguir na esteira do que os documentos orientadores e normativos da Educação Especial na perspectiva inclusiva apregoam: monitoria e cuidado. No item reservado ao planejamento, os profissionais de apoio relatam sobre a falta de tempo para planejamento o que resulta no desenvolvimento de atividades descontextualizadas daquelas realizadas com o restante da classe, já que não possuem em sua carga horária, tempo para planejamento conjunto com os professores regentes. A ausência dos aspectos pedagógicos é evidenciada nas falas dos profissionais de apoio entrevistados haja vista que o trabalho de- senvolvido com os sujeitos da Educação Especial em muitas escolas não passa de atividades improvisadas, já que não há uma organização/planejamento a priori das atividades a serem desenvolvidas com os alunos da Educação Especial. O que de certa forma é condizente com as propostas para a Educação Especial na perspectiva inclusiva em que atribui às salas de recursos a responsabilidade de atuação com atendimento educacional especializado, restando à sala de aula o espaço para a socialização. Além das questões já destacadas, os profissionais de apoio ainda precisam passar por mais um entrave na realização de suas ações nas escolas, ausência de locais adaptados para atividades que requerem locais específicos, como por exemplo, para a realização de troca de fraldas ou vestuário. Da mesma forma, percebe-se a carência de condições de acessibilidade (como rampas para cadeiras de rodas) e de materiais adaptados para o desenvolvimento do trabalho com os alunos. Assim percebe-se que mesmo para desempenhar as funções de monitoria e cuidado ainda não lhes são proporcionadas condições adequadas para tal. As precárias condições com que os profissionais de apoio enfrentam diariamente em seu trabalho não somente foram relatadas por "desabafos" dos entrevistados, mas também vistas, já que em muitas escolas os profissionais de apoio concediam a entrevista em seus horários de "intervalo", horário este diferenciado dos demais profissionais que atuam na escola, em sala de professores 
já vazias, encontravam-se sozinhos os profissionais de apoio no tempo destinado ao seu descanso ou intervalo. Em algumas das escolas visitadas foram encontrados profissionais de apoio que mesmo no tempo destinado ao seu descanso permaneciam junto à criança pela qual era "responsabilizada" no espaço escolar. Uma outra questão que merece destaque refere-se ao esforço destes profissionais que tentam manter viva a sua função de ensinar, mesmo quando não lhes são dadas condições para tal e mesmo quando os documentos legais, normativos e orientadores indicam que esta não é sua função. A pesquisa junto às redes municipais referente ao trabalho do profissional de apoio na Educação Básica oferece subsídios para a compreensão de que este implica em um cargo novo nas redes de ensino. Constitui um processo de intensificação do trabalho docente realizado no âmbito de um cargo precarizado/desvalorizado com relação ao trabalho do professor regente. Explicita, ainda, o modelo de inclusão escolar difundido pelos documentos oficiais ao assumir uma característica de pouca, ou nenhuma ênfase, nas questões pedagógicas. Mantém a prática orientada por diagnósticos reforçada pela realização de cursos que identificam o aluno pelas características do diagnóstico de deficiência.

\section{Referências}

BANCO MUNDIAL. Relatório sobre o desenvolvimento mundial 2000/2001. Luta contra a pobreza. Panorama geral. Washington, 2000.

BRASIL. MEC/SEESP. 7 de janeiro de 2008. Política Nacional de Educação Especial na Perspectiva da Educação Inclusiva. Disponível em: <http://peei.mec.gov.br/arquivos/politica_nacional_educacao_especial.pdf $>$.

. Resolução CNE/CEB n. 4, de 13 de julho de 2010. Institui Diretrizes Operacionais para o Atendimento Educacional Especializado na Educação Básica, modalidade Educação Especial. Brasília, 2009. Disponível em: <http://portal.mec.gov.br/cne/arquivos/pdf/ CEB0201.pdf>. Acesso em: 10 jan. 2010.

. SEESP/ GAB. Nota Técnica $n$. 19, de 8 de setembro de 2010, destinado aos profissionais de apoio para alunos com deficiência e transtornos globais do desenvolvimento matriculados nas escolas comuns da rede públicas de ensino. Disponível em: <http://www. mp.ba.gov.br/atuacao/infancia/educacao/especial>. Acesso em: 11 maio 2011.

. DECRETO 7.611/2011, de 17 de novembro de 2011, que Dispõe sobre a educação especial, o atendimento educacional especializado e dá outras providências. Disponível em: http://www.planalto.gov.br/ccivil_03/_Ato2011-2014/2011/Decreto/D7611.htm. Acesso em: 20 out. 2012. 
. CNE. CEB. Resolução n. 2, de 11 de setembro de 2001, institui as Diretrizes Nacionais para a Educação Especial na Educação Básica. Brasília, 2001. Disponível em: <http://portal. mec.gov.br/cne/arquivos/pdf/CEB0201.pdf>. Acesso em: 17 jan. 2010.

FLORIANÓPOLIS. Edital n. 001/2009. Concurso público do magistério. Disponível em: <http:// www.fepese.ufsc.br/index.php?opti=67>. Acesso em: 10 mar. 2010.

. Edital № 003/2009. Processo seletivo de substitutos. Disponível em: <http://www. fepese.ufsc.br/index.php?opti=67>. Acesso em: 10 mar. 2010.

FLORIANÓPOLIS. Prefeitura Municipal de Florianópolis. Secretaria Municipal de Educação. Documento orientador de educação Especial na rede de ensino de Florianópolis. Florianópolis, 2007.

GARCIA, Rosalba Maria Cardoso. Políticas Públicas de Inclusão: uma análise no campo da educação especial brasileira. 2004. Tese (Doutorado em Educação) - PPGE/CED/Universidade Federal de Santa Catarina, Florianópolis, 2004.

INSTITUTO NACIONAL DE ESTUDOS E PESQUISAS EDUCACIONAIS ANÍSIO TEIXEIRA - INEP/ Censo Escolar/ 2009. Matrícula inicial de alunos das redes municipais de ensino. Disponível em: <http://portal.inep.gov.br/basica-censo-escolar-matricula $>$. Acesso em: 8 mar. 2010.

INSTITUTO BRASILEIRO GEOGRAFIA E ESTATÍSTICA - IBGE. Ensino, matrícula, docentes e rede escolar - 2009. Disponível em: <http://www.cidades.ibge.gov.br/>. Acesso em: 8 mar. 2010.

MARIN, Alda Junqueira. Precarização do trabalho docente. In: OLIVEIRA, D. A.; DUARTE, A. M. C; VIEIRA, L. M. F. Dicionário: trabalho docente. Belo Horizonte: UFMG/Faculdade de Educação, 2010. CD-ROM.

MICHELS, Maria Helena et al. A articulação entre serviço especializado e classe comum: a organização curricular frente a um modelo inclusivo. In: ENCONTRO DE PESQUISA EM EDUCAÇÃO DA REGIÃO SUL - ANPEd Sul, 8., 2010, Londrina. Anais eletrônicos... Londrina: ANPEd Sul, 2010.

OLIVEIRA, Dalila Andrade; GONÇALVES, Gustavo Bruno B.; MELO, Savana D.; FARDIN, Vinicius; MILL, Daniel. Transformações na organização do processo de trabalho docente e o sofrimento do professor. s/d Disponível em: <http://www.redeestrado.org>. Acesso em: 8 jun. 2011.

ORGANIZAÇÃO DAS NAÇÕES UNIDAS PARA A EDUCAÇÃO, A CIÊNCIA E A CULTURA - UNESCO. Declaração de Salamanca e enquadramento da ação: necessidades educacionais especiais. Salamanca, Espanha, 1994.

. Declaração mundial de educação para todos. Plano de ação para satisfazer as necessidades básicas de aprendizagem. Tailândia, 1990.

RANSON, S. The new learning for inclusion and capability: towards community governance in the education action zones. OCDE, 2001. 
SÃO JOSÉ. Edital n. 008/2009. Processo seletivo público. Disponível em:<http://www.fepese. ufsc.br/index.php?opti=67>. Acesso em: 10 mar. 2010.

SHIROMA, Eneida Oto. Política de profissionalização: aprimoramento ou desintelectualização do professor? Intermeio, Campo Grande, v. 9, n. 17, p. 64-83, 2003. Disponível em: <http:// www.gepeto.ced.ufsc.br/det_referencia.php>. Acesso em: 30 set. 2010.

Recebido em agosto de 2013

Aprovado para publicação em dezembro de 2013 